\title{
El núcleo residual del derecho humano al agua en Colombia El papel del discurso económico en su delimitación
}

Le noyau résiduel du droit humain à l'eau potable en Colombie. Le rôle du discours économique dans sa délimitation

The residual nucleus of the human right to water in Colombia. The role of economic discourse in its definition

\section{Pedro Ignacio Bernal}

\section{OpenEdition}

Journals

Edición electrónica

URL: http://journals.openedition.org/bifea/10670

DOI: $10.4000 /$ bifea. 10670

ISSN: 2076-5827

Editor

Institut Français d'Études Andines

Edición impresa

Fecha de publicación: 1 agosto 2019

Paginación: 199-218

ISSN: 0303-7495

Referencia electrónica

Pedro Ignacio Bernal, « El núcleo residual del derecho humano al agua en Colombia

El papel del discurso económico en su delimitación », Bulletin de l'Institut français d'études andines [En línea], 48 (2) | 2019, Publicado el 08 agosto 2019, consultado el 27 noviembre 2020. URL : http:// journals.openedition.org/bifea/10670 ; DOI : https://doi.org/10.4000/bifea.10670

\section{cc) (†) $\odot$}

Les contenus du Bulletin de l'Institut français d'études andines sont mis à disposition selon les termes de la licence Creative Commons Attribution - Pas d'Utilisation Commerciale - Pas de Modification 4.0 International. 


\title{
El núcleo residual del derecho humano al agua en Colombia El papel del discurso económico en su delimitación
}

\author{
Pedro Ignacio Bernal*
}

\section{Resumen}

A partir de un análisis de la naturaleza de los servicios urbanos y de los límites económicos de los derechos sociales, enmarcado en una política de gasto social focalizado, este artículo muestra cómo la jurisprudencia constitucional colombiana reconoce un derecho humano al agua restringido por criterios económicos, favoreciendo así los intereses de las empresas.

Palabras clave: servicios públicos, derecho humano al agua, límites económicos

Le noyau résiduel du droit humain à l'eau potable en Colombie. Le rôle du discours économique dans sa délimitation

\section{Résumé}

Le présent article analyse les services urbains et les limites économiques des droits sociaux, dans le cadre d'une politique de dépenses sociales ciblées, pour montrer comment la jurisprudence constitutionnelle colombienne reconnaît un droit humain à l'eau potable limité par des critères économiques favorables aux intérêts des entreprises.

Mots-clés : services urbains, droit à l'eau potable, limites économiques

Economista de la Universidad Externado de Colombia, D. E. A. de la Universidad de París XII, docente e investigador de la Facultad de Economía, Universidad Externado de Colombia, Bogotá. E-mail: pedro.bernal@uexternado.edu.co 


\title{
The residual nucleus of the human right to water in Colombia. The role of economic discourse in its definition
}

\begin{abstract}
This article analyzes public utilities and the economic limits of social rights, in the context of a policy of targeted social expenditure, in order to show how Colombian constitutional jurisprudence recognizes a human right to water, limited by economic criteria which favor the interests of the water companies.
\end{abstract}

Keywords: Public utilities, human right to water, economic restrictions

En Colombia, a comienzos de la década de 1990, al mismo tiempo que se adoptaba una Constitución progresista que integraba una amplia lista de derechos individuales y colectivos, el propio texto constitucional abría las puertas a la participación privada en la provisión de servicios públicos. El telón de fondo de estos cambios fue la implementación, por vía legal, de políticas neoliberales que reformaron a fondo sectores como el financiero, el laboral, la seguridad social y los servicios públicos domiciliarios. En cuanto a estos últimos, la ley 142 de 1994 puso en marcha un esquema orientado a la privatización por medio de una serie de estímulos y garantías a favor de los intereses empresariales.

La implementación de este régimen legal ha permitido algunos avances en materia de coberturas, pero también ha significado un fuerte aumento de las tarifas de los servicios, con efectos como la reducción de los consumos, una evolución regresiva del gasto y la presencia significativa de hogares desconectados por incapacidad de pagar sus facturas. Como resultado de estas restricciones de acceso al servicio de acueducto, numerosas personas han acudido a la acción de tutela (Constitución Política de Colombia, 1991, art. 86) como medio para acceder al agua potable como derecho fundamental.

El propósito de este artículo es estudiar cómo, desde el discurso jurídico sobre los bienes esenciales tratados como derechos, se ha construido un reconocimiento al derecho humano al agua como derecho fundamental para personas en condiciones de extrema vulnerabilidad. Esta exploración permitirá mostrar que el derecho resultante está restringido por los criterios y principios económicos inscritos en la ley 142 de 1994. La primera parte describe los aspectos básicos de la Constitución colombiana de 1991 y del régimen legal de los servicios públicos domiciliarios como expresión de políticas neoliberales. La segunda presenta algunos indicadores que ilustran las dificultades de acceso al servicio de acueducto como resultado de la implementación de la ley. En la tercera parte se estudia la construcción jurídica de una narrativa sobre los derechos sociales acotados por limitaciones económicas. En la cuarta y última parte, se realiza un análisis de la jurisprudencia de la Corte Constitucional colombiana entre 1992 y 2013, que permite constatar la construcción de un derecho al agua como «núcleo residual» subordinado a los derechos económicos empresariales instituidos en la ley. 


\section{LAS REFORMAS NEOLIBERALES Y LOS SERVICIOS PÚBLICOS}

La globalización neoliberal impuso un modelo que promueve el recorte de los impuestos a las empresas, la reducción de los servicios públicos y su privatización, favoreciendo el acceso a través del mercado a los servicios públicos (Cárdenas Gracia, 2015: 4-8; Paramio, 2009: 52-53). El neoliberalismo apela al Estado de derecho liberal como estrategia para reivindicar un «Estado moderno», en contraste con la planificación del Estado benefactor, y busca desmontar este último para imponer un Estado que garantice los contratos desde un enfoque de derechos individuales plegado a la razón del mercado. Se rescata la noción de libertad individual y el papel regulador de los mercados, con un Estado que interviene en la sociedad y en la economía. La idea de Estado intervencionista en la versión neoliberal no descarta cierta influencia política sobre lo económico, en la que aquel debe intervenir para garantizar la libertad de acción del mercado (Dávalos, 2008: 5-11).

Las reformas neoliberales van acompañadas de la implementación de mecanismos de regulación y vigilancia para que los mercados funcionen lo más cerca posible de condiciones competitivas. En nombre de la competencia se imponen reformas que introducen incentivos a la inversión privada y políticas de desregulación financiera, flexibilización laboral, privatización de activos y servicios públicos y el desmonte de beneficios sociales, con el argumento de eliminar privilegios sociales que no se ciñen al principio de la eficiencia económica (Dávalos, 2008: 11-13).

En América Latina, las políticas de ajuste estructural aplicadas por el Fondo Monetario Internacional frente a la crisis de la deuda, a comienzos de la década del ochenta, fueron la cobertura sobre la cual se produjo la transición hacia la democracia. Más de cuatro décadas después, la mayoría de los países de la región ostentan con orgullo la forma política del Estado Social de Derecho, sin cuestionar si este formato político implica una Constitución neoliberal como estructura jurídica y social (Dávalos, 2008: 20). Otros autores postulan un nuevo constitucionalismo como forma jurídica originada en los cambios de la globalización neoliberal, en el que las constituciones nacionales son la arena donde se expresan diversos poderes. Sin embargo, en este último caso el neoconstitucionalismo incluye expresiones de resistencia a la globalización, por medio del derecho constitucional local, caracterizado por la presencia de derechos fundamentales y por la fuerza interpretativa y progresista de los tribunales constitucionales (Ibarra Serrrano, 2012: 20-23; Matías Camargo, 2013; Rodríguez Garavito, 2009).

En cualquier caso, la incorporación de derechos como garantías constitucionales es paralela a la instauración de políticas neoliberales, de modo que la aplicación efectiva de tales derechos enfrenta en la práctica todo tipo de restricciones. Es en ese marco institucional que la Corte Constitucional colombiana intentará reconocer una larga lista de derechos consagrados en la Carta Política. Para autores como Bernal Pulido (2009: 71-72), los fallos de la Corte Constitucional sobre servicios públicos domiciliarios incluyen dos tendencias: una liberal que promueve la iniciativa privada, la competencia y la eficiencia económica, y otra garantista 
acorde con el Estado social de derecho y la satisfacción de las necesidades básicas de la población. Pero ninguna de ellas, según él, prevalece en forma absoluta sobre la otra y no pueden coexistir pacíficamente, pues están en conflicto.

En Colombia, desde la década de 1990 (bajo el gobierno de César Gaviria: 1990-1994) se introdujeron medidas legislativas de corte neoliberal: reforma de flexibilización laboral (ley 50 de 1990); del sistema de salud y seguridad social (ley 100 de 1993); liberalización y privatización de los servicios públicos domiciliarios (ley 142 de 1994). Paralelamente, se crearon programas sociales focalizados para atender a la población en extrema vulnerabilidad, orientados más a mitigar los efectos de las políticas económicas neoliberales y a evitar los conflictos sociales que a garantizar niveles dignos de existencia a la población. (Díaz Londoño, 2009; Dávalos, 2008: 11-13)

La Constitución Política colombiana de 1991 consagra una amplia lista de derechos, de carácter fundamental así como los derechos económicos, sociales y culturales (Título II, capítulos 1 y 2). Dentro de estos últimos están la salud y el saneamiento ambiental (art. 49), la propiedad privada (art. 58), la libertad económica privada y la libre competencia, en un marco en que el Estado pone límites en función del bien común (art. 333) y actúa como director general de la economía con el fin de mejorar las condiciones de vida de la población (art. 334). Según este último artículo (reformado por el Acto Legislativo 03 de 2011), los fines sociales del Estado deben sujetarse al respeto de la sostenibilidad fiscal, la cual exige la ejecución progresiva de tales fines. Si bien el gasto público social tiene prioridad constitucional, la regla fiscal, que vela por el equilibrio de las finanzas públicas, puede imponer un límite a dicho gasto, aunque sin afectar el «núcleo esencial de los derechos fundamentales». En la Constitución (Título XII, Del régimen económico y de hacienda pública, capítulo 5) los servicios de agua potable y el saneamiento básico son «inherentes a la función social del Estado», por lo cual éste debe velar por su eficiencia y universalidad, sin que ello imponga al Estado la obligación de prestarlos directamente. Ello abrió la posibilidad de su prestación privada. Las funciones exclusivas del Estado son las de regulación, control y vigilancia de los servicios públicos (art. 365).

La Ley 142 de 1994 (régimen de servicios públicos domiciliarios) resulta de un proceso que, al menos desde la década de 1980, venía promoviendo un modelo comercial de gestión en los servicios públicos (Cuervo, 1991; 2005). Se orienta a la privatización de estos servicios y atribuye a los entes estatales funciones específicas de regulación, vigilancia y control. Para ello fueron creadas las comisiones de regulación y la Superintendencia de Servicios Públicos domiciliarios. Este régimen establece una serie de reglas que estimula la entrada de operadores privados, garantizándoles la recuperación de sus inversiones. Algunas de estas reglas son: libertad de competencia (art. 2), estímulo a la inversión privada (art. 3), restricción del derecho de huelga (art. 4), subsidios públicos (arts. 3 y 5) y preferencia a la sociedad por acciones como forma jurídica empresarial (art. 17) (Cuervo, 2005: 33). El régimen jurídico que se aplica a todo tipo de empresas es de las sociedades anónimas privadas (art. 19), al igual que para los actos y contratos de las empresas (arts. 31 y 32 ). 
Se confiere al Estado la responsabilidad de los servicios públicos, por lo cual éste debe garantizar su prestación en condiciones de calidad, universalidad, continuidad y eficiencia; también debe garantizar la competencia y controlar los abusos de las empresas con poder de mercado. El Estado debe también establecer un régimen de tarifas que incorporen subsidios para los usuarios de bajos ingresos (arts. 2 y 3), que permitan a las empresas recuperar sus inversiones y gastos y obtener utilidades (principio de suficiencia financiera), y reflejar las condiciones de eficiencia y productividad de un hipotético mercado competitivo (arts. 87 y 90). Los subsidios en las tarifas para los usuarios de ingresos más bajos no están a cargo de las empresas, sino de los usuarios con mayores ingresos (subsidios cruzados) y de los presupuestos de las entidades públicas tanto de orden nacional como local (subsidios directos).

La relación contractual entre empresa y usuario es de carácter oneroso: una prestación a cambio de dinero y según las estipulaciones fijadas por la empresa. El incumplimiento del pago de las facturas por parte del usuario conlleva la suspensión del servicio (arts. 130 y 140)' ; también se autoriza el cobro de intereses de mora a los usuarios cuando estos han incurrido en incumplimientos y atrasos en los pagos de las facturas. La Corte Constitucional (Sentencia C-150 de 2003) determinó que cuando el usuario no paga el servicio, ello repercute negativamente sobre los que sí pagan, atentando así contra el principio de solidaridad que exige que cada usuario asuma las cargas que le corresponden en virtud de la Constitución, la ley y el contrato. Además, la falta de pago dificulta que las empresas presten los servicios con eficiencia, lo cual va en contravía de los principios sociales consagrados en la Constitución (art. 365) como orientadores de la prestación, la regulación y el control de los servicios públicos. Esta misma sentencia se pronuncia acerca de los servicios públicos domiciliarios así:

... actualmente la idea de gratuidad ha sido abandonada, siendo los servicios públicos, por regla general onerosos... (art. 132)

\section{LOS PROBLEMAS DE ACCESO AL SERVICIO DE ACUEDUCTO}

Entre 2005 y 2018 el porcentaje de viviendas con acceso a una conexión de acueducto en Colombia apenas aumentó tres puntos porcentuales, pasando de $83,4 \%$ a $86,6 \%$ (Departamento Nacional de Estadística-DANE, 2018). Es decir, todavía hay más del $13 \%$ de las viviendas sin acceso a una conexión domiciliaria de agua. Ahora bien, estas cifras no reflejan las condiciones reales del acceso al servicio que frecuentemente se ven afectadas por la mala calidad del agua consumida y/o por un suministro no continuo del servicio, lo cual significa que la cobertura efectiva es inferior a las cifras nominales de coberturas. Con base en una

1 Artículo modificado por el artículo 19 de la ley 689 de 2001, especificando que el tiempo máximo para proceder a la suspensión es de dos periodos de facturación si esta es bimestral y tres periodos de facturación si esta es mensual. 
muestra de empresas de la Superintendencia de Servicios Públicos Domiciliarios, Bernal (2013) concluye que el nivel de calidad del servicio promedio es del 40\%, mientras que el de calidad del agua alcanza el 38\%. Incluso en Bogotá, que presentó los mejores indicadores, la calidad del servicio fue de solo 67\%.

Los aumentos de cobertura tampoco dejan ver el efecto sobre el bienestar de los consumidores por los aumentos en las tarifas, asociados con la aplicación de la ley 142 de 1994. En el periodo 1996-1999, la variación acumulada de las tarifas en las principales ciudades del país, en términos reales, fue superior para los estratos de menores ingresos: $238,1 \%$ para el estrato $1,177,1 \%$ para el estrato $2,132,8 \%$ para el estrato 3, 94,9\% para el estrato 4,77,1\% para el estrato 5, y $57,3 \%$ para el estrato 6 (Contraloría, 2002: 29, Tabla 2). Una de las consecuencias de los aumentos de tarifas es la disminución de los niveles de consumo de los hogares. En Bogotá, por ejemplo, entre 1997 y 2003 el consumo de agua (en millones de metros cúbicos por año) se redujo en un 18\%, y el consumo per cápita en un 38\% (Centro de Investigaciones para el Desarrollo-CID \& Departamento Administrativo de Planeación Distrital, 2004: 48). Además, aumentó la carga del pago de los servicios públicos sobre los ingresos de los hogares más pobres. También en Bogotá, el gasto en servicios públicos como proporción del ingreso de los hogares más pobres (estratos 1, 2 y 3) tendió a duplicarse entre 1997 y 2004, mientras que en los hogares de ingresos medios (estratos 4 y 5) se mantuvo igual y en el estrato 6 disminuyó (CID, 2004) (Ver cuadro 1).

Cuadro 1 - Participación del gasto en servicios públicos en el ingreso de cada uno de los estratos socioeconómicos en Bogotá, 1997 y 2004 (\%)

\begin{tabular}{|c|c|c|}
\hline $\begin{array}{c}\text { Estrato } \\
\text { socioeconómico }\end{array}$ & $\mathbf{1 9 9 7}$ & $\mathbf{2 0 0 4}$ \\
\hline 1 & 4 & 11 \\
\hline 2 & 5 & 10 \\
\hline 3 & 5 & 9 \\
\hline 4 & 5 & 5 \\
\hline 5 & 5 & 5 \\
\hline 6 & 7 & 5 \\
\hline Total & $\mathbf{5}$ & 7 \\
\hline
\end{tabular}

Fuente: CID, 2004: 26

Los hogares que no pueden pagar sus facturas han sido desconectados por las empresas prestadoras, las cuales están autorizadas legalmente para hacerlo cuando los usuarios no cumplen con las reglas contractuales. En Medellín, por ejemplo, en 2010 había 42619 suscriptores desconectados del servicio de agua potable, de los cuales el $41 \%$ suspendidos (con 20 o más cuentas sin pagar) y 59\% cortados (con 70 o más meses sin pagar a la empresa)2. La mayoría de los desconectados

2 La suspensión es la interrupción temporal del servicio por la falta de pago oportuno o por otra de las causales previstas en la ley 142 de 1994 o en el contrato de condiciones uniformes del contrato de 
(95\%) pertenecía a los estratos 1, 2 y 3. Sin embargo, las deudas acumuladas por los usuarios representaron apenas el 0,75\% de las utilidades obtenidas por Empresas Públicas de Medellín (EPM) en 2009 (Instituto Popular de CapacitaciónIPC, 2010).

Entre junio de 2011 y junio de 2012 se presentaron en los municipios de Medellín, Bello y Envigado (departamento de Antioquia) 489 acciones de tutela contra EPM, solicitando la protección de los derechos fundamentales a la vida, la salud, la dignidad humana y el agua potable. En este último caso, se exigió la reconexión del servicio de acueducto y, en algunos casos, la suscripción de acuerdos de pago teniendo en cuenta la limitada capacidad de pago de los reclamantes (Ramírez, 2016: 66).

En Bogotá, en 2004 los hogares con suspensión o corte del servicio de acueducto representaban el 15,6\% del total de los hogares que contaban con una conexión. Los hogares pertenecientes a los estratos 1, 2 y 3 (los más pobres) representaban el 52,5\% de todos los hogares en esta situación (CID, 2004: 52). En los años 2016, 2017 y 2018 (cifras hasta el mes de agosto para este último), las suspensiones y cortes del servicio representaron el $23,9 \%$, 52,8\% y 30,2\%, respectivamente, en relación con el total de conexiones (Superintendencia, 2018) Los estratos 1, 2 y 3 concentraron más del $65 \%$ de las suspensiones y cortes en esos mismos años. Si se agrega el estrato 4, se alcanza el 80\% (ver cuadro 2).

Cuadro 2 - Participación de los cortes y suspensiones del servicio de acueducto en Bogotá para cada estrato o categoría sobre el total de los cortes y suspensiones, 2016, 2017 y 2018

Empresa de Acueducto y Alcantarillado de Bogotá (\%)

\begin{tabular}{|c|c|c|c|}
\hline $\begin{array}{c}\text { Estrato socioeconómico o } \\
\text { categoría }\end{array}$ & $\mathbf{2 0 1 6}$ & $\mathbf{2 0 1 7}$ & $\begin{array}{c}\mathbf{2 0 1 8} \text { (hasta } \\
\text { agosto) }\end{array}$ \\
\hline Estrato 1 & 6,0 & 6,0 & 5,4 \\
\hline Estrato 2 & 25,4 & 25,6 & 26,9 \\
\hline Estrato 3 & 35,5 & 34,5 & 32,9 \\
\hline Estrato 4 & 13,5 & 14,1 & 14,2 \\
\hline Estrato 5 & 4,4 & 4,8 & 5,2 \\
\hline Estrato 6 & 4,7 & 4,5 & 4,5 \\
\hline Comercial & 8,7 & 8,9 & 9,4 \\
\hline Total & $\mathbf{9 8 , 2}$ & 98,4 & 98,5 \\
\hline
\end{tabular}

Fuente: Superintendencia de Servicios Públicos Domiciliarios, 2018. Cálculo de los porcentajes por el autor

servicios públicos; el corte implica la terminación del contrato y por lo tanto la pérdida del derecho al servicio e implica el retiro de la acometida y del medidor. 


\section{EL SERVICIO PÚBLICO DE ACUEDUCTO Y EL DERECHO HUMANO AL AGUA}

La delimitación del derecho al agua en Colombia se inscribe en un marco de políticas de gasto social focalizado propio de un modelo de corte neoliberal. Tal como vimos (supra, sección 1), la ley 142 de 1994 desarrolla un marco normativo dirigido a estimular y a garantizar condiciones de mercado que favorecen los intereses empresariales. La aplicación de este modelo se ha traducido en restricciones de acceso efectivo al agua potable y dinámicas de gasto regresivo entre los hogares de más bajos ingresos (supra, sección 2). En la presente sección mostramos cómo el servicio público esencial de acueducto es asumido como derecho fundamental por medio de un discurso jurídico basado en elementos económicos. Este discurso jurídico-económico es clave para entender la manera como se construye la noción de «núcleo esencial de los derechos fundamentales» que, según nuestra interpretación, contribuye a crear en realidad un «núcleo residual» del derecho humano al agua (infra, sección 4).

El acceso al agua potable genera efectos positivos que se traducen en bienestar individual y colectivo y mayores oportunidades para sus beneficiarios en términos de salud, higiene, alimentación, aprendizaje y productividad; garantiza condiciones de accesibilidad y habitabilidad en los procesos de urbanización; y la conservación de los ecosistemas naturales permite la disponibilidad permanente del recurso hídrico en cantidad y calidad adecuadas para los territorios y las generaciones futuras. De ahí su caracterización como bien mayor (Cuervo, 1997). El servicio público de acueducto y otros como la salud y la educación se suelen considerar como bienes meritorios o «bienes de valor social» (Comisión Económica para América Latina y el Caribe-CEPAL, 2000) pues, pese a ser susceptibles de intercambios de mercado, a partir de consideraciones éticas, sociales y políticas, ninguna persona debería ser excluida de su disfrute. Son expresión concreta de los derechos económicos, sociales y culturales en tanto auténticas preferencias de la sociedad que van más allá de preferencias individuales (Ocampo, 2008: 44-45).

La provisión de bienes como el agua, la electricidad, los transportes y las telecomunicaciones exige cuantiosas inversiones en infraestructuras físicas que suelen representar la mayor parte de los gastos de provisión. La recuperación de estos gastos necesita amplios periodos de amortización, en cuya financiación no participan capitalistas privados, que prefieren delegarlo al Estado (socialización de los gastos de inversión). Lo anterior revela una especial contradicción: por una parte, estos bienes satisfacen necesidades esenciales de consumo de la población y al mismo tiempo son materias primas clave para los procesos productivos; pero, por otra parte, enfrentan grandes dificultades para encontrar los recursos de inversión de las infraestructuras requeridas para proveerlos. En los países en vías de desarrollo estas dificultades son aún mayores, no solo por las restricciones para la generación de recursos públicos (la base fiscal es menor y el aparato fiscal débil frente a poderosos intereses económicos), sino porque además las dinámicas demográfica y urbana suelen incrementar aceleradamente las necesidades frente a las posibilidades de satisfacerlas (Lojkine, 1981; Cuervo, 1991; Jaramillo, 1983). 
Es esa contradicción la que las sociedades deben resolver y que se expresa en la restricción fiscal. La solución principal que han encontrado las sociedades es la financiación pública de estos gastos en infraestructura y la concesión de subsidios para sufragar los consumos de subsistencia de los más pobres. De las dos modalidades de asignación de ese gasto, la universalista es propia del Estado de bienestar que predominó en los países más desarrollados durante el siglo XX, y la focalizadora es empleada actualmente por los gobiernos que aplican políticas neoliberales, Colombia ha optado por esta última. Su aplicación en los servicios de agua potable y saneamiento básico se apoya en las siguientes fuentes: 1) los subsidios públicos directos cuyos recursos provienen sobre todo del presupuesto del Estado nacional; su regulación es establecida por la Constitución, reglamentada por leyes de transferencias territoriales y de regalías; 2) los subsidios cruzados interestratos, regulados por la ley 142 de 1994; y 3) el mínimo vital de agua potable, al cual se refieren las sentencias que estudiaremos y las políticas municipales que lo han adoptado (infra, sección 4).

Este modo de asignación del gasto social se apoya en tres instrumentos: 1) la focalización propiamente dicha, que implica la racionalización del gasto público social, dirigido a los grupos más pobres de la población; 2) la participación privada, apoyada con subsidios a la demanda, mediante el desarrollo de esquemas contractuales público-privados; y 3) la descentralización, con la idea de acercar los beneficiarios de los subsidios a las autoridades encargadas de su asignación (Ocampo, 2008: 42). El «Estado focalizador» que suele enunciar principios y objetivos de equidad y justicia social, es un Estado menesteroso que se concentra en los más necesitados, es decir se caracteriza por una limitada capacidad de convocatoria de la ciudadanía (Ocampo, 2008: 47; Cárdenas, 2015: 19-20, 24). Como veremos, el discurso de derechos humanos que suele acompañar las decisiones de la Corte Constitucional colombiana para garantizar servicios sociales como el agua potable se inspira en ideales universalistas, pero sus efectos se restringen a categorías y prácticas focalizadoras.

Veamos ahora cómo se expresa esta restricción económica en el discurso jurídico referido a estos servicios considerados como derechos constitucionales.

La visión universalista de la política social se basa en una concepción integral de la sociedad y en derechos de igualdad y cohesión social, no como concesiones restringidas o excepcionales que solo favorecen a algunos grupos de la sociedad. Esta tradición permitió la consolidación de los derechos humanos de segunda generación (arts. 22 a 27 de la Declaración Universal de los Derechos Humanos y, posteriormente, Pacto Internacional de los derechos económicos, sociales y culturales-DESC) que promueven la igualdad, la solidaridad y la no discriminación. Estos derechos se agregan y se funden con los derechos de primera generación (libertad, autonomía...). Así, en el Preámbulo de la Declaración Universal de los Derechos Humanos, los DESC son considerados como una extensión del principio de libertad. La universalidad como principio de la política social implica el acceso a servicios sociales básicos, provistos por los Estados como derechos ciudadanos, no como mercancías. Sin embargo, el acceso efectivo a estos bienes está limitado por 
el nivel de desarrollo alcanzado y por el «pacto fiscal» imperante en la sociedad, de manera que la ecuación debe combinar universalidad y restricción fiscal según la siguiente fórmula: «Lo realizable, pero no menos de ello, y lo máximo entre lo realizable» (Ocampo, 2008: 44; CEPAL, 2000).

El discurso de los derechos humanos, por una parte, reivindica el valor del agua potable como soporte esencial e insustituible para la vida, y por otra, recalca la necesidad de reconocer la dimensión económica asociada a los procesos sociales de provisión de estos servicios. El DHA se origina directamente en la proclamación de los derechos y libertades fundamentales del hombre que busca garantizar la satisfacción de necesidades fundamentales. Los derechos inscritos en la Carta de los Derechos del Hombre se enfocan en lograr cuatro objetivos que dan un contenido concreto a una existencia digna: a) proteger la vida y la integridad física de las personas; b) garantizar el ejercicio de los derechos fundamentales y de las libertades individuales; c) eliminar las discriminaciones; y d) garantizar condiciones mínimas de vida (Belaidi, 2010: 354-355). La Observación n. 15 del Consejo Económico y Social de la ONU instituyó un derecho al agua en los siguientes términos:

un suministro suficiente, físicamente accesible y a un costo asequible, de un agua salubre y de calidad aceptable para los usos personales y domésticos de cada quien (Naciones Unidas, 2002).

En este marco de derechos humanos, el agua es «indispensable para tener una vida digna» y constituye «una condición previa para la realización de otros derechos humanos» (Naciones Unidas, 2002). Pese a que en este pronunciamiento el agua es considerada como un bien social y cultural, y condición previa para una vida digna, en nombre de la «escasez» es tratada implícitamente como un bien económico. Este tratamiento permite incluir al agua en las reglas de los intercambios mercantiles y, por lo tanto, autorizar y dar legitimidad a la privatización de los servicios relacionados con el agua. La Declaración de Dublín (1992), por ejemplo, al mismo tiempo que consideraba que es «primordial reconocer el derecho fundamental del hombre al agua salubre y a una higiene adecuada a un precio asequible», también estableció que: «El agua, utilizada para múltiples fines, tiene un valor económico y debería ser reconocida como un bien económico». Al mismo tiempo, la Observación n. ${ }^{\circ} 15$ tiene en cuenta la posible colusión entre distintos derechos, por lo cual considera el problema de la disponibilidad de recursos públicos y, por ende, la necesidad de garantizar el derecho al agua de manera progresiva (Isaza Cardozo, 2014: 8)

La Constitución colombiana distingue entre derechos fundamentales y derechos económicos, sociales y culturales (Título II, capítulos 1 y 2). Un derecho es fundamental por su vínculo directo con principios constitucionales 3 y por su aplicación directa sin que se requiera de una norma legal (Sentencia T-406/1992). Una de las garantías de la eficacia de los derechos fundamentales es su trámite

3 Son principios constitucionales el Estado social de derecho, la democracia participativa y pluralista, el respeto de la dignidad humana, el trabajo, la solidaridad, la prevalencia del interés general sobre el particular, la soberanía popular y la supremacía de la Constitución (Sentencia T-406/1992). 
por medio de la acción de tutela, mecanismo para su protección cuando estos son vulnerados o amenazados; implica una orden de inmediato cumplimiento, pero solo cuando el afectado no dispone de otro medio de defensa judicial para evitar un perjuicio irremediable. La acción de tutela impone un plazo de diez días entre el momento de la solicitud y su resolución (Constitución Política, art. 86). Los derechos fundamentales se dividen entre los de aplicación inmediata ${ }^{4}$ y aquellos que no lo son5, pues su validez supone alguna acción positiva del Estado.

Los derechos económicos, sociales y culturales están en un lugar secundario en términos de su eficacia. Para su reconocimiento el juez debe evaluar la gravedad de la violación del derecho fundamental y las posibilidades económicas para solucionar el problema dentro de una lógica razonable, teniendo en cuenta la escasez de recursos y los propósitos de igualdad y justicia social que señala la Constitución. Así pues, los derechos sociales son derechos prestacionales o programáticos puesto que exigen un esfuerzo presupuestal y logístico del Estado que solo se puede realizar con la debida planeación y arbitrio de recursos mediante el procedimiento fijado en la Constitución. Son derechos prestacionales la salud, la seguridad social, la educación, la atención a la niñez y a la tercera edad, el agua potable y el saneamiento básico. La exigibilidad de derechos prestacionales por vía de tutela se establece por su conexidad con un derecho fundamental, luego de verificarse una violación o amenaza de éste que afecte a una persona que se encuentre en condición de debilidad manifiesta aunada a la imposibilidad material de su familia para darle asistencia, en particular, cuando la completa ausencia de apoyo la priva de su derecho al mínimo vital (Sentencia T-406 de 1992, resaltados fuera del original).

En esta separación entre derechos, y en la restricción económica asociada a los derechos sociales de carácter prestacional, se fundamenta el discurso jurídico que limita el acceso pleno a bienes esenciales como el agua potable. La manera como la Corte Constitucional ha reconocido el derecho fundamental al agua implica adaptarlo a los derechos económicos de los proveedores del servicio. Esto no significa ponerlos en pie de igualdad pues son derechos que están en conflicto: no es posible garantizar plenamente unos sin disminuir o restringir los otros (Bernal Pulido, 2005: 85; Cuéllar, 2005). La jurisprudencia ha desarrollado procedimientos que buscan restringir lo menos posible los derechos sociales fundamentales cuando las políticas públicas amenazan con afectarlos. Se aplican, entonces, principios como el de proporcionalidad cuya finalidad es justificar, mediante un análisis de clara índole económica, la implementación de la medida de política pública, siempre que esta prometa beneficios en términos de un derecho constitucional, que sean superiores a la restricción (costo) sufrida por el derecho fundamental afectado por dicha medida.

4 Son derechos fundamentales de aplicación inmediata la vida, la igualdad, el libre desarrollo de la personalidad, la libertad de conciencia, de cultos y de expresión, la honra, la petición, la circulación, la libertad, el debido proceso, el habeas corpus, la apelación judicial y la participación política, entre otros.

5 Por ejemplo, el trabajo, el asilo, la libre asociación y la sindicalización. 
El principio de proporcionalidad busca que la medida no solo tenga un fundamento legal, sino que sea aplicada de tal manera que los intereses jurídicos de otras personas o grupos no se vean afectados, o que ello suceda en grado mínimo (Bernal Pulido, 2005: 75).

La aplicación de este principio debe cumplir con las siguientes condiciones: 1) ser adecuado para el logro de un fin constitucional válido; 2) ser necesario en el sentido de que no exista otra medida alternativa menos onerosa para alcanzar el fin constitucional buscado; y 3) que sea proporcionado en cuanto que el sacrificio que representa sobre los derechos afectados, no sea mayor que los beneficios que se espera obtener con la adopción de la medida (Sentencia C-022 de 1996, citada por Bernal Pulido, 2005: 77). Entonces, el principio de proporcionalidad es «la restricción de la restricción, el límite de los límites de los derechos fundamentales, el criterio que condiciona la validez de los límites que el Estado impone a los derechos fundamentales» (Bernal Pulido, 2005: 82, 308). La Corte Constitucional debe vigilar que el poder legislativo no limite en exceso los derechos fundamentales, de manera que no se desconozca su «núcleo esencial», entendido este como «el reducto medular invulnerable que no puede ser puesto en peligro por autoridad o particular alguno» (Sentencia C-142 de 2001, citada por Bernal Pulido, 2005: 84).

No obstante, la concreción del núcleo esencial de los derechos y la determinación de las medidas necesarias para realizar ese contenido esencial, es algo complicado, según lo reconocen los propios juristas:

No existen criterios seguros para establecer aquello que constituye el mínimo del fin. Del mismo modo, así se pudiera reconocer el mínimo del fin, subsiste el problema de definir cómo conocer cuáles son las estrategias legislativas mínimas (los medios mínimos) para conseguir este mínimo del fin. De un lado, el juicio acerca de estas estrategias depende de variables económicas que casi nunca ofrecen certezas o fórmulas seguras. La confianza en la intuición de los jueces, presente en la idea de los mínimos, no puede desmentir el hecho de que la elección entre estrategias de acción social para alcanzar los mínimos de los derechos es más bien un asunto de la ciencia económica, para cuya evaluación está más legitimado el legislador (Bernal Pulido, 2005: 320).

Según lo anterior, los límites de los derechos sociales son principalmente económicos:

En este sentido, la doctrina y la jurisprudencia han acuñado la afirmación según la cual los derechos sociales, en todo su ámbito normativo, están sometidos a la 'reserva de los posible' (Bernal, 2005: 321).

Por eso, los derechos sociales son derechos prima facie, «que admiten restricciones legislativas, siempre y cuando sean proporcionadas. Estas restricciones pueden estar justificadas en razón de las limitaciones económicas...» (Bernal Pulido, 2005: $322,326)$. En el marco de esta concepción, si un derecho prestacional como el acceso al agua es admitido como derecho fundamental, su exigibilidad debe ser débil, lo cual supone una garantía mínima, restringida a una cantidad mínima de agua potable (Ramírez Grisales, 2016: 189). 
Pero las restricciones económicas no son restricciones absolutas. El problema de la escasez de recursos debe entenderse en el marco social e histórico en el que se presenta, no como un presupuesto abstracto sin ningún asidero con la realidad. La escasez es un problema relativo, que se plantea en el marco de conflictos distributivos entre diferentes grupos sociales. De ahí que el planteamiento del problema y su expresión jurídica y económica dependen sobre todo de la lucha política y de los canales y mecanismos jurídicos e institucionales mediante los cuales esta se expresa. En este sentido, la definición del núcleo esencial de los derechos fundamentales, incluyendo el DHA, se restringe y subordina a las fuertes barreras impuestas por determinados intereses económicos, de modo que la delimitación del DHA aparece más como un ejercicio de sustracción y su resultado como un residuo: el núcleo residual del derecho humano al agua.

\section{LA DELIMITACIÓN JURISPRUDENCIAL DE UN NÚCLEO RESIDUAL DEL DERECHO AL AGUA}

En Colombia, el DHA ha sido introducido por medio de la acción de tutela concebida para la protección de derechos fundamentales. La Corte Constitucional, por medio de una extensa serie de sentencias de tutela, ha establecido el contenido y alcance de un derecho fundamental al agua, inicialmente resaltando la relación entre el consumo de agua potable y derechos fundamentales como la vida y la dignidad humanas; y posteriormente, refiriéndose al agua como un derecho fundamental autónomo (Isaza Cardozo, 2014:11, 12) En contraste con el enfoque mercantil de la ley, el reconocimiento judicial del agua como derecho; aparecería como una decisión a contracorriente del marco legal. El análisis de la jurisprudencia constitucional del DHA muestra que pese al carácter progresista de los fallos que amparan este derecho, tanto en su contenido como en sus alcances, estos fallos no desvirtúan el marco legal imperante; al contrario, lo ratifican y legitiman. En las sentencias sobre el derecho al agua potable se desarrolla un procedimiento jurisprudencial que lleva a delimitar el conjunto de características que lo definen. Estas características se refieren a los sujetos que tienen acceso a ese derecho y las circunstancias que lo justifican. El procedimiento jurisprudencial que define el núcleo esencial del DHA presenta una tendencia conservadora fuertemente condicionada por criterios económicos.

Pese a que los derechos humanos tienen una vocación universal, las normas internacionales y nacionales subrayan la necesidad de que su reconocimiento se concentre en personas en condición de vulnerabilidad o debilidad manifiesta. Esta prioridad responde al objetivo de focalizar recursos escasos para concentrar las ayudas sociales en quienes más las necesitan. El ordenamiento jurídico colombiano concede prioridad a las personas en condición de pobreza crítica (Sentencia T-432/1992). La jurisprudencia de la Corte Constitucional ha limitado el alcance del derecho al agua como derecho fundamental a los casos en que los reclamantes son sujetos de especial protección constitucional. Se refiere a personas cuyas condiciones de vida las priva de la satisfacción de necesidades 
esenciales para su subsistencia (discapacidad física o mental, niñez, enfermedad, pobreza extrema, desplazamiento forzado, madres cabeza de familia, y personas que ocupan establecimientos carcelarios y hospitales). Estas condiciones se resumen con los términos de debilidad manifiesta y perjuicio irremediable que aluden a la dificultad o imposibilidad que tienen estas personas para satisfacer sus necesidades básicas de manera autónoma (ver también las sentencias T-888/08; T-381/09; T-546/09).

Además, el reconocimiento judicial de este derecho se restringe al uso del agua únicamente para consumo humano (sentencias T-410/03; T-143/10; T-179/13), no para usos diferentes como por ejemplo terrenos o inmuebles deshabitados (sentencias T-413/95 y T-410/03). Tampoco cabe su reconocimiento cuando los reclamantes han realizado reconexiones fraudulentas luego de que se les haya suspendido el suministro de agua por incumplir la obligación de pagar

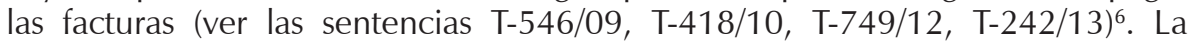
circunstancia más frecuente de reclamación del DHA es la suspensión del servicio por el incumplimiento del pago de la factura, lo cual está relacionado con la caracterización del contrato de servicios públicos como oneroso (supra, num. 1). Debido a que la mayoría de hogares que sufren estos cortes de servicio padecen condiciones de extrema pobreza, es natural que un gran número de sentencias de tutela tengan que ver con demandas relacionadas con esta situación?

La jurisprudencia suele respaldar el carácter oneroso del contrato de servicios, aduciendo que el pago es una condición necesaria para la realización plena y universal de los mandatos constitucionales de eficiencia, continuidad, regularidad y calidad en la prestación de los servicios (Constitución Política, art. 365) (ver sentencias T-614/2010 y C-493/1997). También se argumenta que la pobreza no exime a las personas de sus obligaciones contractuales con las empresas, pues de ello depende no solo la sostenibilidad financiera de estas, sino también la prestación misma de los servicios a otras personas (sentencia T-717/10).

La sentencia T-546/2009 se basa ampliamente en criterios económicos para señalar los límites al reconocimiento del derecho al agua, en particular cuando la suspensión se debe al incumplimiento de pago. Aduce que el no pago pone en riesgo la obligación legal y constitucional de las empresas y del Estado de garantizar una prestación eficiente y continua de los servicios, de modo que el pago es indispensable para garantizarlos; que la viabilidad financiera de las empresas es necesaria para prestar los servicios, y que el incumplimiento repetido de los pagos

6 Excepcionalmente la Corte ha concedido este derecho en casos de reconexión irregular de sujetos de especial protección constitucional. Por ejemplo, si al momento de instaurar y fallar la tutela, dicha reconexión ilegal ya no existía, se reconoce el derecho al agua de SEPC, en especial en el caso de niños y otras personas en estado de indefensión y sin ninguna otra posibilidad de ver reconocido su derecho fundamental al agua (sentencia T-717/10). Se conoce otro caso en el que hubo varias reconexiones ilegales, pero según la Corte se debía considerar si la suspensión del servicio afectaba a SEPC, en especial a menores de edad y a personas enfermas (sentencia T-242/13).

7 En nuestra bibliografía estas sentencias se señalan con un asterisco. Otras sentencias que se originan en este mismo problema son: T-528/92, T-1016/99, T-1432/00, T-740/11, T-752/11, T-348/13 y $\mathrm{T}-573 / 13$. 
va en contra no solo del interés económico de las empresas («de pauperización de su patrimonio», según la expresión usada en la sentencia) sino que puede llevar al colapso e imposibilidad material de la prestación misma, lo cual va en contra de la finalidad social del Estado ligada a los servicios públicos (artículo 365 constitucional). Se afirma, entonces, que la obligación de pagar las facturas es de rango constitucional, pues contribuye a la solidaridad y a la operatividad de las empresas, y por ende a la prestación efectiva de los servicios (ver también la sentencia T-614/10). La misma sentencia llama la atención sobre el hecho de que una prohibición categórica de suspender servicios a personas de estratos bajos, niños y en general a sujetos protegidos constitucionalmente, podría introducir incentivos perversos, es decir promover una cultura de no pago ${ }^{8}$.

Como ya se indicó, el reconocimiento judicial del derecho al agua como derecho fundamental procede si quien reclama demuestra ser un sujeto de especial protección constitucional, no poseer los recursos suficientes para pagar el servicio y no haberse reconectado fraudulentamente. En este caso, cabe la excepción a la regla legal de la suspensión del servicio, siempre y cuando el reclamante realice un acuerdo de pagos con la empresa, considerando su limitada capacidad de pago, y si no puede cumplir, la empresa debe proveer un mínimo de 50 litros/ habitante/día instalando un reductor de flujo como mecanismo para controlar la cantidad máxima provista (ver sentencias T-242/13 y T-864/13). En casos extremos de imposibilidad de cumplimiento reiterado de los acuerdos de pagos, se sugiere que las personas gestionen ante las autoridades municipales el acceso al programa de mínimo vital de agua potable (ver infra) (Sentencias T-717/10, T-242/13 y T-864/13).

En síntesis, el reconocimiento judicial del derecho al agua para personas en condiciones de vulnerabilidad y reconocidas como sujetos de especial protección constitucional, en la medida que se realiza respetando los derechos empresariales, reconocidos legal y constitucionalmente, se lleva a cabo por medio de las siguientes restricciones. La primera restricción es cuantitativa: se reconoce el derecho pero la cantidad de agua se limita al mínimo vital: 50 litros/habitante/ día; la segunda es técnica: para controlar que el agua suministrada a las personas no supere esta cantidad, la empresa debe instalar un reductor de flujo; y la tercera alude a cuestiones económicas y administrativas: las personas deben suscribir un acuerdo de pagos para sufragar las sumas adeudadas a las empresas (ver sentencias T-426/1992, T-270/2007, T-546/2009, T-614/10, T-179/13, T-864/13, T-471/11 y T-242/13). Según la sentencia T-546/2009, la manera de hacer compatibles los derechos de las empresas con los derechos de suministro de agua potable, la vida y la salud de las personas no es suspendiendo totalmente el servicio (pues la suspensión afecta los derechos de sujetos de especial protección constitucional), sino suspendiendo la forma de prestar el servicio, es decir ofrecerles cantidades

8 Finalmente, esta sentencia denegó el derecho reclamado pues previamente los usuarios se reconectaron irregularmente al mismo tiempo que acudieron a la acción de tutela para reclamar su derecho al agua. 
mínimas e indispensables de agua, que según la Organización Mundial de la Salud consiste en un volumen razonable de agua necesario para usos personales y domésticos que se estima entre 50 y 100 litros/habitante/día.

El otorgamiento del mínimo vital de agua se inscribe en una concepción de los derechos humanos como justicia mínima, que reconoce el derecho a una subsistencia también mínima. Este «minimalismo» es cuestionable desde un punto de vista moral, pues aceptar un menor grado para algunos es desconocer el carácter universal de los derechos y por lo tanto el principio de igualdad. Este contenido mínimo del derecho corresponde a un enfoque minimalista de los derechos (Ramírez Grisales, 2016: 184, 190-191) El control del consumo mínimo mediante un dispositivo técnico y la obligación de suscribir acuerdos de pago, son condiciones que se orientan claramente al salvaguardar los intereses de las empresas (Restrepo, 2014: 59-61). Si el derecho al agua solo se otorga a las personas que carecen de la capacidad de pagar por el servicio, pero, por otra parte, no es constitucionalmente admisible la exoneración del deber de pagar las deudas, cómo explicar que la Corte ordene celebrar los acuerdos de pago? La respuesta reside en que las empresas puedan hacer valer su «derecho de crédito», mediante el embargo y remate de la vivienda del titular del derecho, algo que resulta inaceptable si se trata de personas en situación de extrema precariedad y necesidad, lo cual agravaría su situación (Ramírez Grisales, 2016: 61). En este sentido, el acceso al agua como derecho delimitado por la jurisprudencia como «núcleo esencial», da como resultado un derecho restringido y limitado por los derechos económicos de las empresas definidos en la ley, un «núcleo residual» del derecho al agua.

\section{CONCLUSIÓN}

En los últimos años se han realizado varios intentos de reformar la ley y la Constitución con el fin de instituir un mínimo vital de agua gratuito y con mayor alcance que el DHA, instituir un derecho a una cantidad mínima vital de agua que sea gratuita, y cuyo alcance sea mayor al de los fallos de tutela de la Corte Constitucional. Pero ninguno de ellos fue aprobado por el Congreso colombiano que, al igual que la Corte Constitucional, ha respaldado el carácter oneroso de los servicios públicos. Además, teniendo en cuenta que los proyectos de reforma proponen extender este beneficio a una gran parte de la población en condición de pobreza, ello supondría una gran carga para las arcas públicas9. En general, no cuestionan la participación privada, reconociéndoles a las empresas el derecho a recuperar los costos implicados en la provisión del mínimo vital10. La única iniciativa que cuestionaba el modelo privado fue el proyecto de ley 171/2008 (conocido como el Referendo del Agua). Promovido por más de 60 organizaciones

9 Ver proyectos de ley 047/2008, 171/2008, 174/2012, 09/2013, 101/2013 y de Acto Legislativo 054/2008.

10 Proyecto de Acto Legislativo 054/2008, y de ley 047/2008, 174/2012, 101/2013 y de Acto Legislativo 11/2016. 
sociales y con el respaldo de más de 2 millones de votos, sus propósitos básicos eran: declarar el agua potable como derecho fundamental; otorgar un mínimo vital de agua gratuito y universal; dar protección especial y uso prioritario a los ecosistemas hídricos, y que la gestión de los servicios de acueducto y alcantarillado fuera estatal y comunitaria. Sin embargo, esta iniciativa no prosperó en el Congreso colombiano, pues en la Cámara de Representantes sufrió cambios que alteraron sustancialmente su contenido original, debido a lo cual sus promotores apelaron a la plenaria de la Cámara. Pero los ponentes no entregaron informe para un segundo debate y, en consecuencia, se hundió por razones de trámite.

La adopción del mínimo vital de agua por algunos municipios ha sido, entonces, una alternativa en la dirección de beneficiar a la población pobre y vulnerable. Los municipios que lo han adoptado se basan en el criterio de pobreza (viviendas clasificadas en los estratos 1 y 2 en Bogotá y La Estrella y hogares clasificados en condición de vulnerabilidad y pobreza en Medellín y Bucaramanga). Para acceder al beneficio, Medellín exige que la vivienda esté vinculada a una empresa registrada en la Superintendencia de Servicios Públicos, tener conexión a las redes y con medidor funcionando; no tener servicios suspendidos, o realizar acuerdos de pago. Bucaramanga exige que los usuarios estén conectados a la red pública y que cumplan los requisitos legales, además de contar con un medidor individual. En Bucaramanga y La Estrella, también es necesario que los usuarios suscriban acuerdos de pago con la empresa. En Bogotá, inicialmente el decreto 485/2011 que adoptó el mínimo vital solo incluyó al estrato 1 y exigía que los suscriptores con deudas pendientes suscribieran acuerdos de pago con la empresa. Posteriormente, el decreto 064/2012 no solamente extendió el beneficio al estrato 2, sino que también derogó el artículo 5 del decreto 485/2011 que imponía las condiciones que se acaban de mencionar. Es decir, Bogotá es la única ciudad del país que ha adoptado una política de acceso al agua como derecho incondicionado, aunque limitado a los hogares que habitan viviendas pertenecientes a los estratos 1 y 2 .

\section{Referencias citadas}

BELAIDI, N., 2010 - L'eau, un enjeu de justice environnementale. In: L'eau mondialisée. La gouvernance en question (G. Schneier-Madanes, ed.): 352-365; París: La Découverte.

BERNAL PULIDO, C., 2005 - El derecho de los derechos. Escritos sobre la aplicación de los derechos fundamentales, 417 pp.; Bogotá: Universidad Externado de Colombia.

BERNAL PULIDO, C., 2009 - El neoconstitucionalismo y la normatividad del derecho, 398 pp.; Bogotá: Universidad Externado de Colombia.

BERNAL, P. I., 2013 - Indicadores del servicio de acueducto y aglomeración urbana en Colombia. Territorios, 29: 77-94.

CÁRDENAS GRACIA, J., 2015 - Las características jurídicas del neoliberalismo. Cuestiones constitucionales. Revista Mexicana de Derecho Constitucional, 32, enero-junio: 3-44. 
CENTRO DE INVESTIGACIONES PARA EL DESARROLLO-CID \& DEPARTAMENTO ADMINISTRATIVO DE PLANEACIÓN DISTRITAL, 2004 - La equidad de las tarifas de los servicios públicos y su impacto en la capacidad de pago de los hogares de Bogotá D. C.

COMISIÓN ECONÓMICA PARA AMÉRICA LATINA Y EL CARIBE-CEPAL, 2000 - Equidad, desarrollo y ciudadanía, 334 pp.; CEPAL.

CONTRALORÍA GENERAL DE LA REPÚBLICA DE COLOMBIA, 2002 - Servicios públicos domiciliarios: perspectivas de la Contraloría general de la República con la participación ciudadana, 68 pp.

CUÉLLAR, M. M., 2005 - La prueba de razonabilidad y la estabilidad de las reglas de juego. Revista de Economía Institucional, 7 (12) Enero-Junio: 13-42.

CUERVO, L. M., 1991 - La historia del sector de acueductos y alcantarillados en Colombia. De la Ley 35 de 1936 al Plan de Ajuste Sectorial, 87 pp.; Bogotá: Centro de Investigación y Educación Popular-Cinep. Serie Informes de Investigación, 4.

CUERVO G., L. M., 1997 - El agua potable como bien mayor. Revista Regulación, 2: 135160; Bogotá: Comisión de Regulación de Agua Potable y Saneamiento Básico.

CUERVO, L. M., 2005 - Servicios públicos domiciliarios en Colombia: la reforma diez años después. Revista Territorios, 14: 27-55.

DÁVALOS, P., 2008 - Neoliberalismo político y "Estado Social de Derecho"; alai: América Latina en movimiento. Disponible en la página web www.alainet.org (fecha de publicación 19/06/2008).

DEPARTAMENTO NACIONAL DE ESTADÍSTICA (DANE), 2018 - Censo nacional de población y vivienda 2018. Colombia. Disponible en https: www.dane.gov.co// index.php/estadisticas-por-tema/pobreza-y-condiciones-de-vida-2018/comovivimos. Consultado el 27 de noviembre de 2018.

DÍAZ LONDOÑO, J., 2009 - Estado social de Derecho y neoliberalismo en Colombia: estudio del cambio social a finales del siglo XX. Antropología Social, 11, enerodiciembre: 205-228.

IBARRA SERRANO, F., 2012 - Neoliberalismo y neoconstitucionalismo: 15-26; s.e.

INSTITUTO POPULAR DE CAPACITACIÓN-IPC, 14 de octubre de 2010 -. Desconectados de servicios públicos: la cara de la pobreza de Medellín. Agencia de prensa. Disponible en: http://www.ipc.org.co/agenciadeprensa/index.php/2010/10/14/ desconectados-de-servicios-publicos-la-cara-de-la-pobreza-en-medellin/ Consultado el 27 de noviembre de 2018.

ISAZA CARDOZO, G. D., 2014 - El derecho al agua y el mínimo vital en el marco del servicio público domiciliario de acueducto en Colombia; Universidad del Rosario, Facultad de Jurisprudencia. Tesis de maestría en Derecho Administrativo.

LOJKINE, J., 1981 - El marxismo, el Estado y la cuestión urbana, 342 pp.; México: Siglo XXI Editores.

JARAMILLO, S., 1983 - Crisis de los medios de consumo colectivo urbano y capitalismo periférico. Revista Desarrollo y Sociedad, No 12: 127-145; Bogotá: Universidad de los Andes.

MATÍAS CAMARGO, S. R., 2013 - Neoliberalismo, neoconstitucionalismo y democracia. Diálogos de saberes, 39, julio-diciembre: 69-86. 
OCAMPO, J. A., 2008 - Las concepciones de la política social: universalismo versus focalización. Nueva Sociedad, 215, mayo-junio: 36-61.

PARAMIO, L., 2009 - La socialdemocracia, 85 pp.; Madrid: Libros de la Catarata.

RAMÍREZ GRISALES, R. S., 2016 - El acceso al agua potable: un deber estatal. Cómo el servicio público de acueducto garantiza el derecho social fundamental de acceso al agua potable, 270 pp.; Bogotá: Universidad Externado de Colombia.

RESTREPO, E., 2014 - Análisis jurisprudencial del acceso al agua potable para el consumo humano; Bogotá: Universidad Nacional de Colombia, Facultad de Minas, Medellín. Tesis de maestría en Medio Ambiente y Desarrollo.

RODRÍGUEZ GARAVITO, C., 2009 - La globalización del Estado de derecho. El neoconstitucionalismo, el neoliberalismo y la transformación institucional en América Latina, 84 pp.; Bogotá: Ediciones Uniandes.

SUPERINTENDENCIA DE SERVICIOS PÚBLICOS DOMICILIARIOS DE COLOMBIA -SSPD, 2018 - Evaluación integral de prestadores. Empresa de Acueducto y Alcantarillado de Bogotá, EAAB, E. S. P., 94 pp.; Bogotá: Superintendencia de Servicios Públicos Domiciliarios.

\section{Normatividad colombiana}

Constitución Política de Colombia (1991)

Ley 142 de 1994

Ley 689 de 2001, que modifica parcialmente la ley 142 de 1994

Ley 047 de 2008

Ley 171 de 2008

Ley 174 de 2012

Ley 09 de 2013

Ley 101 de 2013

Decreto 485 de 2011, Bogotá

Decreto 064 de 2012, Bogotá

Acto Legislativo 054 de 2008

Acto Legislativo 11 de 2016

Jurisprudencia de la Corte Constitucional (sentencias)

T-406 de 1992, M. P. Ciro Angarita

T-426 de 1992, M. P. Eduardo Cifuentes

T-432 de 1992*, M. P. Simón Rodríguez

T-528 de 1992

T-413 de 1995, M. P. Alejandro Martínez

C-493 de 1997, M. P. Fabio Morón

T-1016 de 1999

T-1432 de 2000

C-150 de 2003, M. P. Manuel J. Cepeda 
T-410 de 2003, M. P. Jaime Córdoba

T-270 de $2007^{*}$, M. P. Jaime Araujo

T-888 de 2008, M. P. Monroy

T-381 de 2009, M. P. Jorge Pretelt

T-546 de 2009*, M. P. María Calle

T-143 de 2010, M. P. María Calle

T-418 de 2010*, M. P. María Calle

T-614 de 2010*, M. P. Ernesto Vargas

T-717 de 2010*, M. P. María Calle

T-471 de 2011*, M. P. María Calle

T-740 de 2011

T-749 de 2012*, M. P. María Calle

T-752 de 2011

T-179 de 2013*, M. P. Gabriel Mendoza

T-242 de 2013*, M. P. Luis Vargas

T-348 de 2013

T-573 de 2013

T-864 de 2013*, M. P. Alberto Rojas

\section{Normatividad internacional}

NACIONES UNIDAS, 2002 - Consejo Económico y Social. Comité de Derechos Económicos, Sociales y Culturales. Observación general N. ${ }^{\circ} 15$ sobre el derecho al agua.

Declaración de la Conferencia Internacional sobre el Agua y el Medio Ambiente, Dublín (1992) 